\title{
Hemistepsin A inhibits T0901317-induced lipogenesis in the liver
}

\author{
Jae Kwang Kim ${ }^{1,2, \#}$, Il Je Cho ${ }^{1, \#}$, Eun Ok Kim ${ }^{1}$, Dae Geon Lee ${ }^{1}$, Dae Hwa Jung ${ }^{1,3}$, Sung Hwan Ki ${ }^{4}$, Sae Kwang Ku ${ }^{1, *} \mathcal{E}$ \\ Sang Chan Kim, ${ }^{1, *}$ \\ ${ }^{1}$ College of Korean Medicine, Daegu Haany University, Gyeongsan 38610, ${ }^{2}$ Korean Medicine-Application Center, Korea Institute of \\ Oriental Medicine, Daegu 41062, ${ }^{3}$ Hani Bio Co., Ltd, Daegu 41059, ${ }^{4}$ College of Pharmacy, Chosun University, Gwangju 61452, Korea
}

\begin{abstract}
Hemistepsin A ( $\mathrm{HsA})$ is a guaianolide sesquiterpene lactone that inhibits hepatitis and liver fibrosis. We evaluated the effects of $\mathrm{HsA}$ on liver X receptor (LXR)-mediated hepatic lipogenesis in vitro and in vivo. Up to $10 \mu \mathrm{M}, \mathrm{HsA}$ did not affect the viability of HepG2 and Huh7 cells. Pretreatment with 5-10 $\mu \mathrm{M}$ HsA significantly decreased the luciferase activity of the LXR response element, which was transactivated by T0901317, GW 3965 , and $L X R \alpha /$ retinoid $X$ receptor $\alpha$ overexpression. In addition, it significantly inhibited the mRNA expression of $L X R \alpha$ in HepG2 and Huh7 cells. It also suppressed the expression of sterol regulatory element-binding protein-1c and lipogenic genes and reduced the triglyceride accumulation triggered by T0901317. Intraperitoneal injection of HsA (5 and $10 \mathrm{mg} / \mathrm{kg}$ ) in mice significantly alleviated the T0901317-mediated increases in hepatocyte diameter and the percentage of regions in hepatic parenchyma occupied by lipid droplets. Furthermore, HsA significantly attenuated hepatic triglyceride accumulation by restoring the impaired expression of LXR $\alpha$-dependent lipogenic genes caused by T0901317. Therefore, based on its inhibition of the LXR $\alpha$-dependent signaling pathway, HsA has prophylactic potential for steatosis. [BMB Reports 2021; 54(2): 106-111]
\end{abstract}

\section{INTRODUCTION}

Steatosis (fatty liver) is the pathologic state in which hepatocytes contain more than $5 \%$ fat. This can be caused by overeating, alcohol consumption, viral infection, hepatotoxins, and other causes. The prevalence of nonalcoholic fatty liver is increa-

*Corresponding authors. Sae Kwang Ku, Tel: +82-53-819-1549; Fax: +82-53-819-1860; E-mail: gucci200@hanmail.net; Sang Chan Kim, Tel: +82-53-819-1862; Fax: +82-53-819-1860; E-mail: sckim@dhu. ac.kr

${ }^{\#}$ These authors contributed equally to this work.

https://doi.org/10.5483/BMBRep.2021.54.2.111

Received 26 May 2020, Revised 30 June 2020, Accepted 21 July 2020

Keywords: Fatty liver, Hemistepsin A (HsA), Liver X receptor, Sterol regulatory element-binding protein-1c, T0901317 sing worldwide as a result of an increasingly sedentary lifestyle and excess food intake. Although nonalcoholic fatty liver is considered not to cause serious liver damage, it can progress to nonalcoholic fatty liver disease (NAFLD), which involves nonalcoholic steatohepatitis, fibrosis, cirrhosis, and cancer (1). Because there are no approved drugs for advanced NAFLD, it must be appropriately managed at an early stage.

Liver $X$ receptors (LXRs) are type II nuclear receptors that activate de novo lipogenesis in the liver (2). In the absence of ligands, LXRs interact with retinoid X receptor (RXR) $\alpha$ and bind to the LXR response element (LXRE), which has a 5'-AGGTCA-3' direct repeat separated by four nucleotides. The conformational change in LXR, which occurs by ligand binding, promotes recruitment of the coactivator complex, resulting in transactivation of target genes. These include sterol regulatory element-binding protein (SREBP)-1c, a transcription factor essential for hepatic lipogenesis (2). In addition, LXR directly or in conjunction with SREBP-1c increases lipogenesis by inducing the production of fatty acid synthase (FASN), stearoyl-CoA desaturase-1 (SCD-1), and acetyl-CoA carboxylase (ACC) $(2,3)$. Two isoforms of LXRs are expressed in mammals, each with different tissue distributions: LXR $\alpha$ is primarily expressed in metabolically active organs/tissues including the liver, whereas LXR $\beta$ is ubiquitously expressed (4). Although both LXR $\alpha$ and LXR $\beta$ are expressed in the liver, the hepatic expression of LXR $\alpha$ is closely associated with the severity of NAFLD in humans (5). In addition, genetic ablation of LXR impairs T0901317 (a synthetic LXR ligand)-mediated hypertriglyceridemia in mice (6), suggesting that $L X R \alpha$ is the predominant isoform regulating lipogenesis in the liver. Hence, inhibition of LXR $\alpha$ activation and its triggering of the expression of target genes shows potential as a strategy for managing fatty liver.

Sesquiterpene lactones (STLs) are secondary metabolites widely distributed in the plant kingdom and are anti-feeding agents; that is, they protect plant from herbivory (7). Although all STLs have three isoprenoids with an $\alpha$-methylene- $\gamma$-lactone moiety, more than 5,000 different structures and 30 subtypes have been identified from diverse plants including Hemistepta lyrata Bunge (Bunge) $(7,8)$. Hemistepsin A ( $\mathrm{HsA})$ belongs to the guaianolide subtype of STL; it is isolated from $H$. lyrata

ISSN: 1976-670X (electronic edition)

Copyright (C) 2021 by the The Korean Society for Biochemistry and Molecular Biology

(c) This is an open-access article distributed under the terms of the Creative Commons Attribution Non-Commercial License (http://creativecommons.org/licenses/by-nc/4.0) which permits unrestricted non-commercial use, distribution, and reproduction in any medium, provided the original work is properly cited. 
and shows antifungal activity and cytotoxicity toward cancer cells $(8,9)$. We recently reported that HsA decreases proinflammatory responses in macrophages by inhibiting the nuclear factor-kappa B (NF-kB) signaling pathway and inducing the expression of nuclear factor E2-related factor 2 (Nrf2)-dependent antioxidant genes (10). The end result is attenuation of the fulminant hepatitis induced by lipopolysaccharide/galactosamine in mice (10). In addition, HsA promotes apoptosis of activated hepatic stellate cells by inhibiting the NF- $\mathrm{KB}$ and Akt signaling pathways, which in turn helps alleviate carbon tetrachloride-induced fibrosis in mice (11). Although HsA may have hepatoprotective potential, its effect on nonalcoholic steatosis is unknown. Therefore, we evaluated the effects of $\mathrm{HsA}$ on T0901317-mediated hepatic lipogenesis in vitro and in vivo.

\section{RESULTS}

HsA inhibits T0901317-induced LXR $\alpha$ expression

We first assessed the viability after HsA-pretreated HepG2 and Huh7 cells $(1-10 \mu \mathrm{M}, 1 \mathrm{~h})$ were exposed to $10 \mu \mathrm{M}$ T0901317 for $24 \mathrm{~h}$. HsA at up to $10 \mu \mathrm{M}$ did not affect cell viability compared to T0901317-treated cells (Fig. 1A). Next, reporter gene assays using an LXRE-driven luciferase plasmid were conducted to investigate whether $\mathrm{HsA}$ inhibits the transactivation of LXR $\alpha$. Treatment with T0901317 (10 $\mu \mathrm{M}, 18 \mathrm{~h})$ increased the LXRE luciferase activity in HepG2 cells. However, pretreatment with 5 and $10 \mu \mathrm{M}$ HsA decreased LXRE
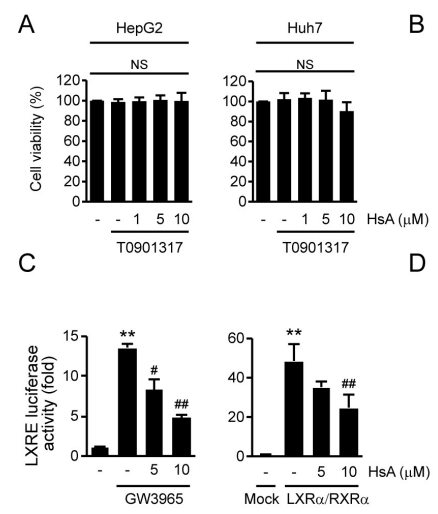

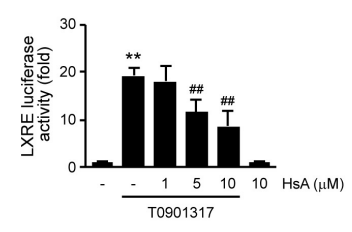

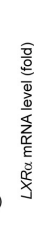

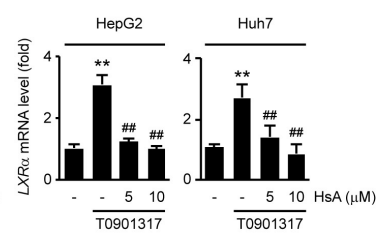

Fig. 1. Hemistepsin A (HsA) inhibits T0901317-induced expression of LXR $\alpha$. Relative viabilities of cells treated with $\mathrm{HsA}$ in the presence of T0901317 were determined using an MTT assay (A). HepG2 cells were transfected with the LXRE reporter plasmid with or without the $L X R \alpha / R X R \alpha$ expression plasmids. Luciferase activities were determined after transfected cells were treated with HsA, T0901317 (B), and GW3965 (C, left). pcDNA ${ }^{\mathrm{TM}}$ 3.2/N5DEST was used for mock transfection $(C$, right). Relative mRNA levels of $L X R \alpha$ were determined by real-time PCR (D). **P $<$ 0.01 versus untreated controls or mock transfection; ${ }^{\#} \mathrm{P}<0.05$, ${ }^{\# \# P}<0.01$ versus T0901317, GW3965, or LXR $\alpha / R X R \alpha$. NS: not significant. luciferase activity compared to that in T0901317-treated cells. $\mathrm{HsA}(10 \mu \mathrm{M})$ alone did not affect luciferase activity (Fig. 1B). Additional LXRE reporter gene assays were conducted to confirm the inhibitory effects of HsA on LXR $\alpha$ transactivation. $\mathrm{HsA}(5$ and $10 \mu \mathrm{M}$ ) inhibited the LXRE-driven luciferase activity, which was increased by GW3965 (3 $\mu$ M; another LXR ligand) (Fig. 1C, left) and by ectopic expression of LXR $\alpha / R X R \alpha$ (Fig. 1C, right).

Because LXR $\alpha$ ligands autonomously increase LXR $\alpha$ expression (12), next, we evaluated the expression level of LXR $\alpha$. The LXR $\alpha$ mRNA level was increased in HepG2 and Huh7 cells exposed to T0901317 (10 $\mu \mathrm{M}, 12 \mathrm{~h})$. However, the T0901317-mediated induction of $L X R \alpha$ was inhibited by pretreatment with 5 and $10 \mu \mathrm{M} \mathrm{HsA}$ (Fig. 1D).

\section{HsA attenuates T0901317-induced lipogenesis in vitro}

Next, we explored the effects of $\mathrm{HsA}$ on the expression of SREBP-1c. HsA (5 and $10 \mu \mathrm{M}$ ) inhibited the T0901317- induced mRNA level of SREBP-1C in Huh7 cells (Fig. 2A). It also decreased the SREBP-1c protein level in HepG2 and Huh7 cells (Fig. 2B). The results from an SREBP response element (SREBPRE) reporter gene assay revealed that T0901317-mediated transactivation of SREBP-1c was inhibited by 5 and $10 \mu \mathrm{M} \mathrm{HsA}$ (Fig. $3 \mathrm{~A})$. Moreover, induction of the expression of LXR $\alpha /$ SREBP1c-dependent lipogenic genes (e.g., FASN, SCD-1, and ACC) was suppressed by HsA pretreatment (Fig. 3B and C). Although pretreatment with $5 \mu \mathrm{M} \mathrm{HsA}$ tended to decrease the T0901 317-mediated elevated FASN and ACC protein levels in HepG2 cells, there were no significant differences compared to T0901 317-treated cells (Fig. 3C).

To further explore HsA-mediated inhibition of lipogenic genes, Huh7 cells were stained with oil red $\mathrm{O}$ and their triglyceride levels were quantified after treatment with T0901317 in the presence or absence of HsA. HsA $(10 \mu \mathrm{M}, 24 \mathrm{~h})$ reduced the T0901317-mediated accumulation of oil red
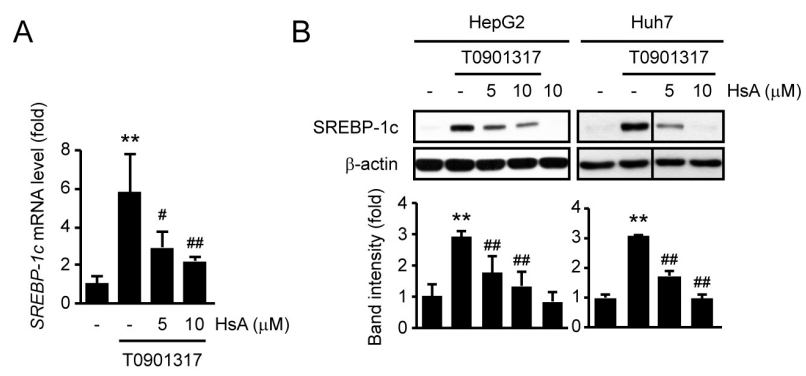

Fig. 2. HsA decreases T0901317-induced SREBP-1c expression. Huh7 and HepG2 cells were treated with 5-10 $\mu \mathrm{M}$ HsA (1 h) and $10 \mu \mathrm{M}$ T0901317 (12 h). Relative mRNA (A) and protein (B) levels of SREBP-1C determined by real-time PCR and Western blotting, respectively. Lines in the right panel of (B) indicate cropped images of the same membrane with the same exposure. $* * \mathrm{P}<0.01$ versus untreated controls; ${ }^{\#} \mathrm{P}<0.05$, ${ }^{\# \#} \mathrm{P}<0.01$ versus T0901317. 


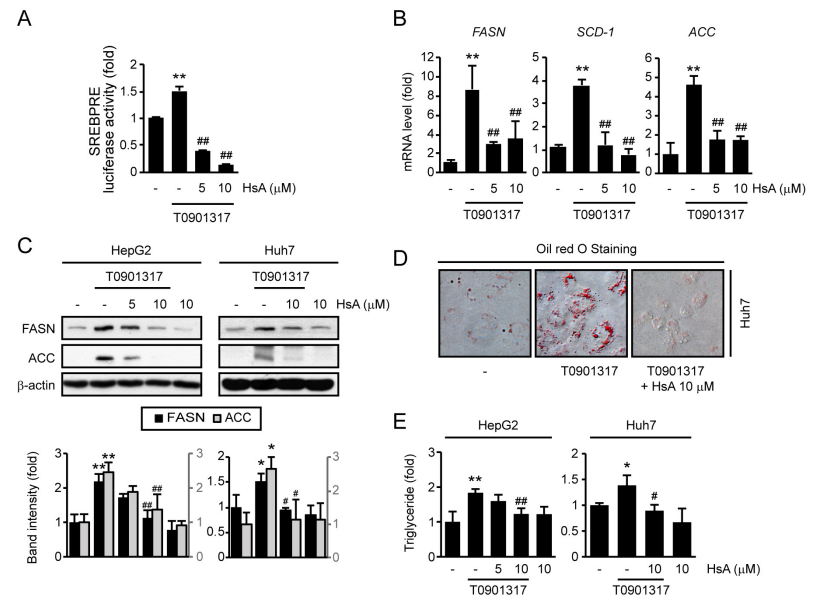

Fig. 3. HsA attenuates T0901317-induced lipogenesis. HsA-pretreated cells $(5-10 \mu \mathrm{M}, 1 \mathrm{~h})$ were exposed to T0901317 for 18 (A), 12 (B), or $24 \mathrm{~h}$ (C-E). An SREBPRE reporter gene assay was conducted using HepG2 cells (A). The relative mRNA and protein levels of lipogenic genes ( $\mathrm{B}$ and $\mathrm{C}$ ) were determined. The cells were stained with oil red $\mathrm{O}(\mathrm{D})$, and levels of triglycerides $(\mathrm{E})$ were measured. ${ }^{*} \mathrm{P}<0.05,{ }^{* *} \mathrm{P}<0.01$ versus untreated controls; ${ }^{\#} \mathrm{P}<0.05$, ${ }^{\# \#} \mathrm{P}<$ 0.01 versus T0901317.

O-stained lipid droplets (Fig. 3D) and triglycerides (Fig. 3E, right). An HsA-mediated reduction in triglycerides was also noted in HepG2 cells (Fig. 3E, left).

\section{HsA decreases T0901317-induced lipogenesis in mice}

Next, 5 or $10 \mathrm{mg} / \mathrm{kg} \mathrm{HsA}$ was intraperitoneally injected into C57BL 6 mice once daily for 3 days, and $25 \mathrm{mg} / \mathrm{kg}$ T0901317 was orally administered at $1 \mathrm{~h}$ after $\mathrm{HsA}$ injection (Fig. 4A). Biochemical analyses of serum indicated that there were no differences in alanine aminotransferase (ALT) and aspartate aminotransferase (AST) levels between vehicle- and T0901317treated mice. In addition, HsA injection in combination with T0901317 did not affect the ALT and AST levels compared to T0901317-treated mice. The AST level was slightly, but significantly, increased in mice injected with only $\mathrm{HsA}(10 \mathrm{mg} / \mathrm{kg}$ ) (Fig. 4B). Moreover, the T0901317-mediated increase in the relative liver weight was attenuated by $10 \mathrm{mg} / \mathrm{kg} \mathrm{HsA}$ (Fig. 4C). Hematoxylin and eosin- and oil red O-staining indicated that T0901317 increased the diameter of hepatocytes and the accumulation of lipid droplets, but $\mathrm{HsA}$ ( 5 and $10 \mathrm{mg} / \mathrm{kg}$ ) inhibited these T0901317-mediated changes (Fig. 4D). Furthermore, impaired serum and hepatic levels of triglyceride by T0901317 were restored by HsA (10 mg/kg) injection (Fig. 4E).

To confirm the inhibitory effects of HsA on hepatic lipogenesis, the mRNA levels of genes associated with $L X R \alpha$-dependent lipogenesis were determined (Fig. 4F). T0901317 decreased the LXR $\alpha$ mRNA level, and HsA (10 mg/kg) partly, but significantly, prevented the reduction in the $L X R \alpha$ mRNA level in hepatic tissues. As expected, T0901317 increased the

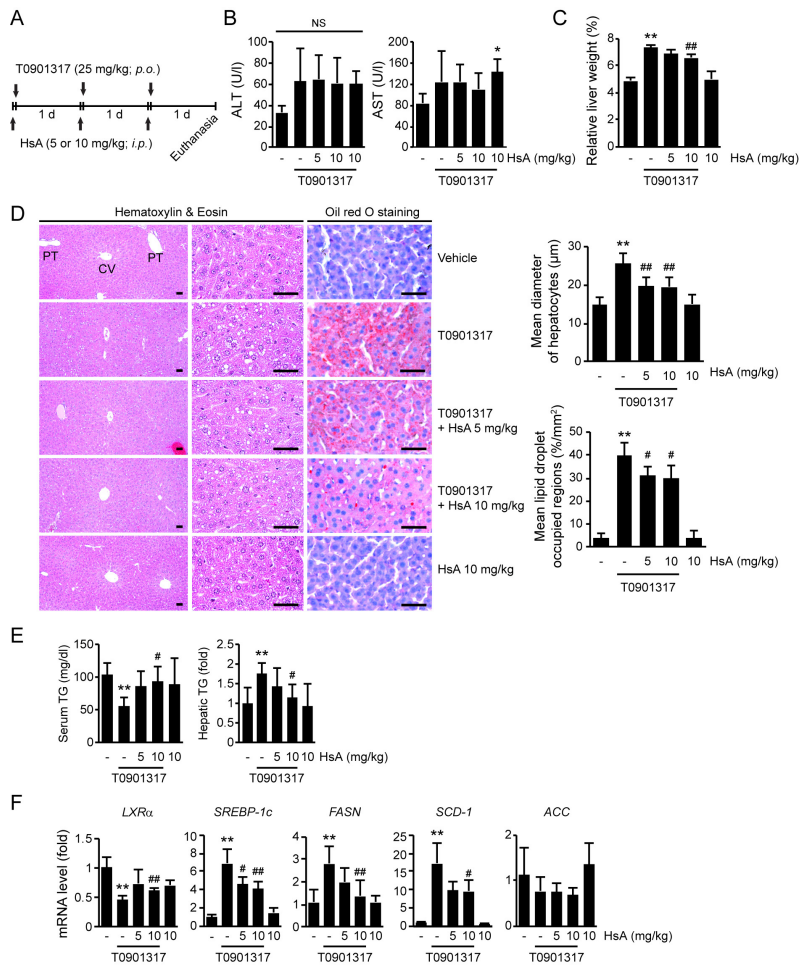

Fig. 4. HsA alleviates T0901317-induced lipogenesis in mice. Animal experimental procedure (A). ALT (B, left), AST (B, right), and triglyceride ( $E$, left) levels in serum and relative liver weights $(C)$ were measured after euthanizing the mice. The mean diameters of hepatocytes and the lipid droplet-occupied regions ( $D$, right) were calculated from hepatic tissues stained with hematoxylin and eosin and oil red $O$ (D, left). Scale bars indicate $60 \mu \mathrm{m}$. The levels of triglycerides ( $\mathrm{E}$, right) and the mRNA levels of lipogenic genes $(\mathrm{F})$ were measured in hepatic tissues. $* \mathrm{P}<0.05$, **P $<0.01$ versus vehicle group; ${ }^{\#} \mathrm{P}<0.05,{ }^{\#} \mathrm{P}<0.01$ versus T0901317. CV: central vein, NS: not significant, PT: portal triad, TG: triglyceride.

mRNA levels of SREBP-1C, FASN, and SCD-1 in hepatic tissues. Compared to T0901317, 5 and $10 \mathrm{mg} / \mathrm{kg}$ HsA decreased the SREBP-1C mRNA. However, the FASN and SCD-1 mRNA levels were only reduced in mice treated with $10 \mathrm{mg} / \mathrm{kg} \mathrm{HsA}$. The mRNA level of ACC did not differ among the treatment groups.

\section{DISCUSSION}

Because T0901317 activates LXR $\alpha$ more potently than LXR $\beta$ and other nuclear receptors (e.g., farnesoid $X$ receptor and pregnane $X$ receptor) $(13,14)$, it has been used as an LXR ligand in studies of the pathophysiological role of LXR $\alpha$. In this work, we found that HsA alleviated hepatic lipogenesis by inhibiting T0901317-mediated LXR $\alpha$ activation and the expression of its target genes in vitro and in vivo. In addition, it inhibited the elevated LXRE luciferase activity induced by 
GW3965 treatment or LXR $/ \mathrm{RXR} \alpha$ expression. Therefore, the inhibition of hepatic lipogenesis by $\mathrm{HsA}$ is not mediated by its regulation of other nuclear receptors.

HsA significantly restored the T0901317-mediated changes in the mRNA level of $L X R \alpha$. In agreement with a previous report (12), T0901317 increased LXR $\alpha$ expression in hepatocyte-derived cells (Fig. 1D). However, three T0901317 administrations significantly reduced the hepatic $L X R \alpha \mathrm{mRNA}$ level in mice (Fig. 4F). Although the role of T0901317 in insulin level is unclear, insulin increases hepatic lipogenesis by inducing LXR $\alpha$ expression (15). T0901317 reportedly impairs glucosemediated insulin secretion in pancreatic islets (16) and decreases the insulin level in $d b / d b$ mice fed a high-fat diet (17). In addition, T0901317 promotes palmitate- and glucose-mediated apoptosis of pancreatic $\beta$ cells $(18,19)$. Therefore, the reduction in hepatic $L X R \alpha$ mRNA level caused by T0901317 may be a result of decreased secretion of insulin in the pancreas. The discrepant in vitro and in vivo results showing $L X R \alpha$ mRNA expression induced by T0901317, and the effects of $\mathrm{HsA}$ and T0901317 on other extrahepatic tissues need to be further resolved.

LXR $\alpha$-mediated gene expression can be regulated by posttranslational modification (e.g., phosphorylation) of $L X R \alpha$, and adenosine 5'-monophosphate-activated protein kinase (AMPK) downregulates the activity of LXR $\alpha$ and SREBP-1c via direct phosphorylation $(3,20,21)$. In addition, AMPK inhibits fatty acid synthesis by inhibitory phosphorylation of ACC and facilitates autophagy to reduce lipid accumulation in hepatocytes (22). Moreover, leucodin, another guaianolide-subtype STL, inhibits ethanol-mediated lipid accumulation by activating AMPK (23). To explore the possibility that $\mathrm{HsA}$ inhibits hepatic lipogenesis via AMPK and/or autophagy activation, Huh7 cells were preincubated with chemical inhibitors of AMPK or autophagy and subsequently treated with $\mathrm{HsA}$ and T0901317. Our additional results showed that the HsA-mediated inhibition of SREBP-1C was sustained after pretreatment with the chemical inhibitors (Supplementary Fig. $1 \mathrm{~A}$ and $\mathrm{B}$ ). This suggests that HsA alleviates T0901317-mediated activation of the LXR $\alpha$ SREBP-1c signaling pathway in a manner independent of AMPK and autophagy activation.

We previously reported that inhibition of Akt as well as activation of p38 mitogen-activated protein kinase (MAPK) and c-Jun $\mathrm{N}$-terminal kinase contribute to the HsA-mediated prevention of hepatic inflammation and fibrosis $(10,11)$. Sustained activation of the phosphoinositide 3-kinase/Akt signaling pathway by phosphatase and tensin homolog deficiency provokes nonalcoholic steatohepatitis in mice (24). In addition, p70 ribosomal S6 kinase, a downstream factor of Akt, enhances LXR $\alpha$ activity (3), suggesting that HsA inhibits LXR $\alpha$-mediated hepatic lipogenesis by modulating the Akt-dependent signaling pathway. However, at least under our experimental conditions, pretreatment with Akt inhibitors did not decrease T0901317induced SREBP-1c expression. Moreover, MAPK inhibitors did not significantly alter the HsA-mediated SREBP-1c reduction
(Supplementary Fig. 1C and D). Although HsA inhibited T09 01317-mediated hepatic lipogenesis, further study is needed to identify the major signaling molecules associated with HsA-mediated inactivation of LXR $\alpha$ and SREBP-1C.

Lipid accumulation is necessary but not sufficient for progression from simple steatosis to the more serious NAFLD; other insults are also required. For instance, overproduction of fatty acids accelerates hepatocyte death by promoting oxidative stress and mitochondrial dysfunction, which amplifies the inflammatory response intended to clear damaged hepatocytes (1). Hence, oxidative stress and inflammation are implicated in the development of advanced NAFLD. Deletion of $\mathrm{Nrf2}$, a master transcription factor for the protection of cells from oxidative stress, exacerbates hepatic steatosis and inflammation in mice fed a methionine- and choline-deficient diet (25). Moreover, several natural products inhibit NAFLD by activating Nrf2-dependent antioxidant genes (26). Interestingly, our results showed that $\mathrm{HsA}$ significantly increased nuclear expression of $\mathrm{Nrf} 2$, transactivated the luciferase activity of an antioxidant response element-harboring reporter gene, and increased the mRNA levels of Nrf2-depenent antioxidant genes (e.g., heme oxygenase 1, glutamate-cysteine ligase catalytic subunit, and sestrin 2) in hepatocyte-derived cells (Supplementary Fig. 2A-C). In addition, T0901317-mediated hepatic lipid peroxidation and protein nitrosylation were significantly reduced in HsA-treated mice (Supplementary Fig. 2D). Moreover, HsA suppresses proinflammatory responses in Tolllike ligand-stimulated macrophages and induces apoptosis of activated hepatic stellate cells by downregulating the NF- $\kappa B$ signaling pathway $(10,11)$. Therefore, the antioxidant and anti-inflammatory effects of HsA may together prevent progression to advanced NAFLD. In conclusion, HsA ameliorated lipogenesis by inhibiting the LXR $\alpha$-SREBP-1c signaling pathway in T0901317-stimulated hepatocyte-derived cells as well as in the mouse liver. Therefore, HsA has prophylactic and therapeutic potential for fatty liver.

\section{MATERIALS AND METHODS}

\section{Reagents}

$\mathrm{HsA}$ was isolated from $H$. lyrata as previously reported (11). T0901317 was supplied by Cayman Chemical (Ann Arbor, MI, USA). Anti-SREBP1 was purchased from Santa Cruz Biotechnology (Santa Cruz, CA, USA). Anti-FASN, anti-ACC, and horseradish peroxidase-conjugated secondary antibodies were obtained from Cell Signaling Technology (Beverly, MA, USA). Thiazolyl blue tetrazolium bromide (MTT), GW3965, $\beta$-actin antibody, oil red $\mathrm{O}$, hematoxylin, eosin, and other reagents were supplied by Sigma-Aldrich (St. Louis, MO, USA).

\section{Cell culture and treatment}

HepG2 and Huh7 cells (human hepatocyte-derived cells) were supplied by American Type Culture Collection (Manassas, VA, USA) and Korean Cell Line Bank (Seoul, Korea), respectively. 
The cultured cells were pretreated with 1-10 $\mu \mathrm{M} \mathrm{HsA}$ for $1 \mathrm{~h}$ and subsequently exposed to either T0901317 (10 $\mu \mathrm{M})$ or GW3965 $(3 \mu \mathrm{M})$ for the indicated time periods.

\section{Cell viability assay}

The treated cells were incubated with MTT $(0.5 \mathrm{mg} / \mathrm{ml})$ for $2 \mathrm{~h}$, and $\mathrm{A}_{570}$ was measured using a Synergy HTX Multi-Mode Plate Reader (BioTek, Winooski, VT, USA). Relative cell viability was calculated as a percentage of untreated controls.

\section{Reporter gene assay}

Reporter plasmids (LXRE and SREBPRE) and expression plasmids (LXR $\alpha$ and RXR $\alpha$ ) were provided, as previously described (3). pRL-SV40, a reporter plasmid expressing Renilla luciferase, was obtained from Promega (Madison, WI, USA). LXRE or SREBPRE reporter plasmid (300 ng) was transiently transfected with pRL-SV40 (40 ng) into HepG2 cells, as previously reported (11). For some experiments, LXR $\alpha$ and RXR $\alpha$ (300 ng each) were co-transfected with LXRE reporter plasmid, and equal amounts of pcDNA ${ }^{\mathrm{TM}}$ 3.2/N5-DEST plasmid (Invitrogen, Carlsbad, CA, USA) were used for mock transfection. The relative luciferase activities were calculated as the firefly luciferase activity divided by Renilla luciferase activity.

\section{Real-time polymerase chain reaction (PCR)}

Isolation of RNA, reverse transcription, real-time PCR, and relative quantification of specific mRNAs were carried out as previously described (11). Gene-specific primers are listed in Supplementary Table 1.

\section{Western blot analysis}

Preparation of whole-cell protein lysates, Western blot analysis, and chemiluminescence detection were conducted, as previously described (11). Band intensities of proteins of interest were analyzed using ImageJ software (National Institutes of Health, Bethesda, MD, USA) and normalized to those of $\beta$-actin.

\section{Oil red O staining of Huh7 cells}

Treated cells were fixed in $100 \%$ ethanol, stained with oil red O (2 mg/ml in 60\% isopropanol) for $10 \mathrm{~min}$, and visualized under a light microscope (Eclipse Ti-U; Nikon, Kanagawa, Japan).

\section{Quantification of triglycerides}

Triglyceride levels in cultured cells or hepatic tissues were quantified using a Triglyceride Quantification Assay Kit (Abcam, Cambridge, UK) according to the manufacturer's instructions and normalized to the protein concentration.

Animal experiments and measurement of relative liver weight Animal experiments were approved by the Institutional Animal Care and Use Committee of Daegu Haany University (Approval No. DHU2018-016). Forty C57BL/6 mice (6-weeks-old males; Saeron Bio, Euiwang, Republic of Korea) were maintained under standard conditions as previously described (11). Mice ( $\mathrm{N}=8$ per group) were intraperitoneally injected with 5 or $10 \mathrm{mg} / \mathrm{kg} \mathrm{HsA}$ dissolved in corn oil once daily for three consecutive days. To induce steatosis, T0901317 (25 mg/kg) in $1 \%$ carboxymethylcellulose and $1 \%$ Tween 20 was orally administered three times at $1 \mathrm{~h}$ after $\mathrm{HsA}$ injection. An equal volume of corn oil and carboxymethyl cellulose/Tween 20 were administered to vehicle group. Dosages of $\mathrm{HsA}$ and T0901317 were chosen based on previous studies $(10,11)$ and a preliminary study (data not shown), respectively. All mice were euthanized $24 \mathrm{~h}$ after the last T0901317 administration, and the liver and blood were collected. The relative liver weights were calculated as the percentage of liver weight to body weight.

\section{Serum biochemistry}

Serum levels of ALT, AST, and triglyceride were measured using a blood chemistry analyzer (Dri-Chem NX500i; Fuji Medical System, Tokyo, Japan).

\section{Tissue staining and histopathology}

Hepatic sections were stained with hematoxylin and eosin or oil red $\mathrm{O}$, as previously described (27). The hepatocyte diameter ( $\mu \mathrm{m} /$ hepatocytes) was calculated as the mean diameter of 10 hepatocytes in hematoxylin and eosin-stained tissues. The regions occupied by lipid droplets ( $\% / \mathrm{mm}^{2}$ of hepatic parenchyma) were calculated as the proportion of oil red $\mathrm{O}$ stained area in a restricted-view field of hepatic parenchyma.

\section{Statistical analysis}

All numerical results are expressed as the mean \pm standard deviation (SD) of at least three independent experiments (in vitro assay) or eight mice (in vivo assay). The One-way analysis of variance was conducted to assess the significance of differences among experimental groups, followed by Tukey's honestly significant difference or Dunnett's T3 test. P values less than 0.05 were considered statistically significant.

\section{ACKNOWLEDGEMENTS}

This study was supported by the National Research Foundation of Korea (NRF) funded by Korea government (MSIP)(Grant No. 2018R1A5A2025272 and 2018R1A2B6007514).

\section{CONFLICTS OF INTEREST}

The authors have no conflicting interests.

\section{REFERENCES}

1. Ding $L$, Oligschlaeger $Y$, Shiri-Sverdlov $R$ and Houben $T$ (2020) Nonalcoholic fatty liver disease; in Handbook of experimental pharmacology, Springer, Berlin, Heidelberg, 
Germany

2. Wang B and Tontonoz $P$ (2018) Liver $X$ receptors in lipid signalling and membrane homeostasis. Nat Rev Endocrinol $14,452-463$

3. Hwahng SH, Ki SH, Bae EJ, Kim HE and Kim SG (2009) Role of adenosine monophosphate-activated protein kinase-p70 ribosomal S6 kinase-1 pathway in repression of liver X receptor-alpha-dependent lipogenic gene induction and hepatic steatosis by a novel class of dithiolethiones. Hepatology 49, 1913-1925

4. Repa JJ, Liang G, Ou J et al (2000) Regulation of mouse sterol regulatory element-binding protein-1c gene (SREBP1c) by oxysterol receptors, LXRalpha and LXRbeta. Genes Dev 14, 2819-2830

5. Ahn SB, Jang K, Jun DW, Lee BH and Shin KJ (2014) Expression of liver $\mathrm{X}$ receptor correlates with intrahepatic inflammation and fibrosis in patients with nonalcoholic fatty liver disease. Dig Dis Sci 59, 2975-2982

6. Zhang Y, Breevoort SR, Angdisen J et al (2012) Liver LXR $\alpha$ expression is crucial for whole body cholesterol homeostasis and reverse cholesterol transport in mice. J Clin Invest 122, 1688-1699

7. Pardilla-Gonzalez GF, Dos Santos FA and Da Costa FB (2016) Sesquiterpene lactones: more than protective plant compounds with high toxicity. Crit Rev Plant Sci 35, 18-37

8. Jang DS, Ha TJ, Yang MS and Park KH (1999) Hemistepsins with cytotoxic activity from Hemisteptia lyrata. Planta Med 65, 765-766

9. Lee JR, Jung DH and Park MK (2013) Antifungal activities of Hemistepsin A and B isolated from Hemistepta lyrata Bunge against dandruff-causing microbes Malassezia obutusa. Kor Soc Biotechnol Bioeng 28, 74-79

10. Kim JK, Lee JE, Jung EH et al (2018) Hemistepsin A ameliorates acute inflammation in macrophages via inhibition of nuclear factor- $\mathrm{\kappa} B$ and activation of nuclear factor erythroid 2-related factor 2. Food Chem Toxicol 111, 176-188

11. Kim JK, Han NR, Park SM et al (2020) Hemistepsin A alleviates liver fibrosis by inducing apoptosis of activated hepatic stellate cells via inhibition of nuclear factor- $\mathrm{kB}$ and Akt. Food Chem Toxicol 135, 111044

12. Endo-Umeda K, Uno S, Fujimori K et al (2012) Differential expression and function of alternative splicing variants of human liver $X$ receptor $\alpha$. Mol Pharmacol 81, 800-810

13. Mitro N, Vargas L, Romeo R, Koder A and Saez E (2007) T0901317 is a potent PXR ligand: implications for the biology ascribed to LXR. FEBS Lett 581, 1721-1726

14. Schultz JR, Tu H, Luk A et al (2000) Role of LXRs in control of lipogenesis. Genes Dev 14, 2831-2838

15. Chen G, Liang G, Ou J, Goldstein JL and Brown MS
(2004) Central role for liver $X$ receptor in insulin-mediated activation of Srebp-1c transcription and stimulation of fatty acid synthesis in liver. Proc Natl Acad Sci U S A 101, $11245-11250$

16. Maczewsky J, Sikimic J, Bauer C et al (2017) The LXR ligand T0901317 acutely inhibits insulin secretion by affecting mitochondrial metabolism. Endocrinology 158, 2145-2154

17. Dong Y, Gao G, Fan H, Li S, Li X and Liu W (2015) Activation of the liver $X$ receptor by agonist TO901317 improves hepatic insulin resistance via suppressing reactive oxygen species and JNK pathway. PLoS One 10, e0124778

18. Liang H, Zhong Y, Zhou S and Li QQ (2011) Palmitic acid-induced apoptosis in pancreatic $\beta$-cells is increased by liver $X$ receptor agonist and attenuated by eicosapentaenoate. In Vivo 25, 711-718

19. Choe SS, Choi AH, Lee JW et al (2007) Chronic activation of liver $\mathrm{X}$ receptor induces beta-cell apoptosis through hyperactivation of lipogenesis: liver $X$ receptor-mediated lipotoxicity in pancreatic beta-cells. Diabetes 56, 15341543

20. Kwon SM, Hong SM, Lee YK, Min S, and Yoon G (2019) Metabolic features and regulation in cell senescence. BMB Rep 52, 5-12

21. Li Y, Xu S, Mihaylova MM et al (2011) AMPK phosphorylates and inhibits SREBP activity to attenuate hepatic steatosis and atherosclerosis in diet-induced insulin-resistant mice. Cell Metab 13, 376-388

22. Fullerton MD (2016) AMP-activated protein kinase and its multifaceted regulation of hepatic metabolism. Curr Opin Lipidol 27, 172-180

23. Shang $Y$, Li XF, Jin MJ et al (2018) Leucodin attenuates inflammatory response in macrophages and lipid accumulation in steatotic hepatocytes via P2x7 receptor pathway: A potential role in alcoholic liver disease. Biomed Pharmacother 107, 374-381

24. Horie Y, Suzuki A, Kataoka E et al (2004) Hepatocytespecific Pten deficiency results in steatohepatitis and hepatocellular carcinomas. J Clin Invest 113, 1774-1783

25. Sugimoto H, Okada K, Shoda J et al (2010) Deletion of nuclear factor-E2-related factor-2 leads to rapid onset and progression of nutritional steatohepatitis in mice. Am J Physiol Gastrointest Liver Physiol 298, G283-G294

26. Jadeja RN, Upadhyay KK, Devkar RV and Khurana S (2016) Naturally occurring Nrf2 activators: potential in treatment of liver injury. Oxid Med Cell Longev 2016, 3453926

27. Choi BR, Cho IJ, Jung SJ et al (2020) Lemon balm and dandelion leaf extract synergistically alleviate ethanolinduced hepatotoxicity by enhancing antioxidant and antiinflammatory activity. J Food Biochem 44, e13232 